Molecules, 2007, 12, 679-693

\title{
molecules
}

ISSN 1420-3049

http://www.mdpi.org

Full Paper

\section{Screening Non-colored Phenolics in Red Wines using Liquid Chromatography/Ultraviolet and Mass Spectrometry/Mass Spectrometry Libraries}

\author{
Jianping Sun ${ }^{1,2}$, Feng Liang ${ }^{3}$, Yan Bin ${ }^{2}$, Ping $\mathrm{Li}^{3}$ and Changqing Duan ${ }^{1, *}$ \\ ${ }^{1}$ Center for Viticulture and Enology, College of Food Science \& Nutritional Engineering, China \\ Agriculture University, 10083 Beijing, People's Republic of China \\ ${ }^{2}$ Cofco Wines \& Spirits, Co. Ltd, 100005 Beijing, People’s Republic of China \\ 3 Agilent Technologies Co. Ltd, 100022 Beijing, People’s Republic of China
}

* Author to whom correspondence should be addressed; E-mail: chqduan@yahoo.com.cn; Tel: (+86)-10-62737136; Fax: (+86)-10-62737136;

Received: 13 December 2006; in revised form: 24 March 2007 / Accepted: 29 March 2007/ Published: 30 March 2007

\begin{abstract}
Liquid chromatography/ultraviolet (LC/UV) and mass spectrometry/mass spectrometry (MS/MS) libraries containing 39 phenolic compounds were established by coupling a LC and an ion trap MS with an electrospray ionization (ESI) source, operated in negative ion mode. As a result, the deprotonated $[M-H]^{-}$molecule was observed for all the analyzed compounds. Using MS/MS hydroxybenzoic acid and hydroxycinnamic acids showed a loss of $\mathrm{CO}_{2}$ and production of a $[M-\mathrm{H}-44]^{-}$fragment and as expected, the UV spectra of these two compounds were affected by their chemical structures. For flavonol and flavonol glycosides, the spectra of their glycosides and aglycones produced deprotonated $[M-\mathrm{H}]^{-}$and $[A-\mathrm{H}]^{-}$species, respectively, and their UV spectra each presented two major absorption peaks. The UV spectra and MS/MS data of flavan-3-ols and stilbenes were also investigated. Using the optimized LC/MS/MS analytical conditions, the phenolic extracts from six representative wine samples were analyzed and 31 phenolic compounds were detected, 26 of which were identified by searching the LC/UV and MS/MS libraries. Finally, the presence of phenolic compounds was confirmed in different wine samples using the LC/UV and LC/MS/MS libraries.
\end{abstract}


Keywords: Non-colored phenolic compounds, Red wines, LC-UV, LC-MS/MS

\section{Introduction}

Phenolics, important secondary metabolites in the grape berry, play a critical role in determining the organoleptic characteristics of berries and wines. In particular they contribute to wine characteristics such as color, flavor, astringency and bitterness [1-3]. Moreover, phenolic compounds are associated with cardiovascular benefits, such as reducing platelet aggregation and modulating eicosanoid synthesis. Recently, the antioxidant activity of phenolic compounds toward human low-density lipoprotein (LDL) has been evaluated in vitro [4-11]. As a result, the study of phenolic compounds, such as the amounts and species found in red wine, where they are more abundant than in white wine, has attracted considerable attention among the food safety community.

The phenolic compounds in red wines mainly comprise Isimple phenolic acids (e.g. hydroxybenzoic acid and hydroxycinnamic acid) and complicated polyphenols (e.g. flavonols, anthocyanin and tannins) which are mainly derived from grape skins and seeds during the vinification process [12], or from yeast metabolites and aging in oak barrels.

Reverse-phase, high-performance, liquid-chromatography (RP-HPLC), with diode array detection (DAD) detector, is widely applied for the analysis of these compounds in wine due to its high sensitivity and easy operation [13-17]. However, the UV spectra of some phenolic compounds are very similar, making their identification ambiguous. Analytical technology for phenolic structures in grapes and wines was thus developed using LC-MS and multiple MS/MS (MSn) stages with an ESI source operating in the negative mode [18-22]. With LC-MS, differences of phenolic compositions and structures could be identified, and some information such as origin and age of wine, grape varieties and winemaking technique could be characterized, so nowadays LC-MS is considered the best analytical technique for studying phenolic compounds in grape and wines [23, 24].

However, it takes a lot of time and standards to analyze large-scale wine samples. For this reason, it would be of interest to establish LC/UV and MS/MS libraries for the identification of real wine samples in order to reduce the amount of work required, which has been not reported so far. The purpose of this research was to compile LC/UV and MS/MS libraries using 39 phenolic standards and to apply them to investigate the phenols present in different wine samples. The work should provide a substantial basis for quality control and fingerprint identification of different wines.

\section{Results and Discussion}

\section{Study of the UV spectra and (-)ESI-MS/MS of phenolic standards}

The HPLC gradient elution profile was optimized using different ratios of water and methanol containing different concentrations of acetic acid (0.2-1.0\%). The results showed that all of the phenols were well separated by linear gradient elution with a mobile phase consisting of water and methanol with $1 \%$ acetic acid. To determine the most effective ionization mode for the phenolic standards (250 $\mathrm{mg} \mathrm{L}^{-1}$ ), atmospheric pressure chemical ionization (APCI) or a ESI source in positive- or negative-ion 
modes were investigated The results indicated that the ESI source at negative-ion mode with a MS/MS activation energy of $1.0 \mathrm{~V}$ was best for the analysis of low-molecular phenolic compounds, which coincided with the previous reports [23, 25]. Based on these optimized conditions, 39 phenolic standards were then analyzed by LC/UV-ESI-MS/MS. The results are listed in Table 1 . At the same time, we compiled LC/UV and MS/MS libraries for identifying phenolic compounds in wine samples.

Figure 1. Structures and sources of purchased phenolic standards<smiles>[R]c1cc(C(=O)O)c([R])c([R4])c1[R]</smiles>

Hydroxybenzoic acid<smiles>[R]c1cc(/C=C/C(=O)O)cc([R])c1[R2]</smiles>

Hydroxycinnamic acid<smiles>[R]c1cc(C2Oc3cc(O)cc(O)c3C[C@H]([R3])[C@@H]2C)cc([R2])c1O</smiles>
Gallate

\begin{tabular}{|c|c|c|c|c|c|c|}
\hline \multicolumn{2}{|c|}{ Hydroxybenzoic acids } & $\mathrm{R}_{1}$ & $\mathrm{R}_{2}$ & $\mathrm{R}_{3}$ & $\mathrm{R}_{4}$ & Source \\
\hline \multicolumn{2}{|c|}{ Gallic acid } & $\mathrm{H}$ & $\mathrm{OH}$ & $\mathrm{OH}$ & $\mathrm{OH}$ & Sigma $^{1}$ \\
\hline \multicolumn{2}{|c|}{ Protocatechuic acid } & $\mathrm{H}$ & $\mathrm{OH}$ & $\mathrm{OH}$ & $\mathrm{H}$ & Sigma \\
\hline \multicolumn{2}{|c|}{ Vanillic acid } & $\mathrm{H}$ & $\mathrm{H}$ & $\mathrm{OH}$ & $\mathrm{OCH}_{3}$ & Aldrich $^{2}$ \\
\hline \multicolumn{2}{|l|}{ Syringic acid } & $\mathrm{H}$ & $\mathrm{OCH}_{3}$ & $\mathrm{OH}$ & $\mathrm{OCH}_{3}$ & Sigma \\
\hline \multicolumn{2}{|c|}{ p-Hydroxybenzoic acid } & $\mathrm{H}$ & $\mathrm{H}$ & $\mathrm{OH}$ & $\mathrm{H}$ & Aldrich \\
\hline \multicolumn{2}{|c|}{ Salicylic acid } & $\mathrm{OH}$ & $\mathrm{H}$ & $\mathrm{H}$ & $\mathrm{H}$ & Sigma \\
\hline \multicolumn{2}{|l|}{ Gentisic acid } & $\mathrm{OH}$ & $\mathrm{H}$ & $\mathrm{H}$ & $\mathrm{OH}$ & Aldrich \\
\hline \multicolumn{2}{|c|}{ Hydroxycinnamic acids } & $\mathrm{R}_{1}$ & $\mathrm{R}_{2}$ & $\mathrm{R}$ & & Source \\
\hline \multicolumn{2}{|l|}{ Caffeic acid } & $\mathrm{H}$ & $\mathrm{OH}$ & $\mathrm{O}$ & $\mathrm{H}$ & Sigma \\
\hline \multicolumn{2}{|c|}{ p-Coumaric acid } & $\mathrm{H}$ & $\mathrm{OH}$ & $\mathrm{H}$ & & Sigma \\
\hline \multicolumn{2}{|c|}{ Sinapic acid } & $\mathrm{OCH}_{3}$ & $\mathrm{OH}$ & & $\mathrm{CH}_{3}$ & Sigma \\
\hline \multicolumn{2}{|l|}{ Ferulic acid } & $\mathrm{OCH}_{3}$ & $\mathrm{OH}$ & $\mathrm{H}$ & & Fluka $^{3}$ \\
\hline \multicolumn{2}{|c|}{ trans-Cinnamic acid } & $\mathrm{H}$ & $\mathrm{H}$ & $\mathrm{H}$ & & Aldrich \\
\hline \multicolumn{2}{|l|}{ Flavan-3-ols } & $\mathrm{R}_{1}$ & $\mathrm{R}_{2}$ & $\mathrm{R}$ & & Source \\
\hline \multicolumn{2}{|l|}{$(+)$-Catechin } & $\mathrm{OH}$ & $\mathrm{H}$ & $\mathrm{O}$ & $\mathrm{H}$ & Sigma \\
\hline \multicolumn{2}{|c|}{ (-)-Epicatechin } & $\mathrm{OH}$ & $\mathrm{H}$ & $\mathrm{O}$ & $\mathrm{H}$ & Sigma \\
\hline \multicolumn{2}{|c|}{ (-)-Gallocatechin gallate } & $\mathrm{OH}$ & $\mathrm{OH}$ & G & iallate & Sigma \\
\hline \multicolumn{2}{|c|}{ (-)-Epigallocatechin gallate } & $\mathrm{OH}$ & $\mathrm{OH}$ & $\mathrm{G}$ & iallate & Sigma \\
\hline \multicolumn{2}{|c|}{ (-)-Epicatechin gallate } & $\mathrm{H}$ & $\mathrm{OH}$ & $\mathrm{G}$ & iallate & Sigma \\
\hline \multicolumn{2}{|c|}{ (-)-Gallocatechin } & $\mathrm{OH}$ & $\mathrm{OH}$ & $\mathrm{O}$ & $\mathrm{H}$ & Sigma \\
\hline \multicolumn{2}{|c|}{ (-)-Epigallocatechin } & $\mathrm{OH}$ & $\mathrm{OH}$ & $\mathrm{O}$ & $\mathrm{H}$ & Sigma \\
\hline Flavonols & $\mathrm{R}_{1}$ & $\mathrm{R}_{2}$ & $\mathrm{R}_{3}$ & & $\mathrm{R}_{4}$ & Source \\
\hline Quercetin & $\mathrm{H}$ & $\mathrm{OH}$ & $\mathrm{H}$ & & $\mathrm{OH}$ & Sigma \\
\hline Myricetin & $\mathrm{H}$ & $\mathrm{OH}$ & $\mathrm{OH}$ & & $\mathrm{OH}$ & Sigma \\
\hline Kaempferol & $\mathrm{H}$ & $\mathrm{H}$ & $\mathrm{H}$ & & $\mathrm{OH}$ & Sigma \\
\hline Morin & $\mathrm{OH}$ & $\mathrm{H}$ & $\mathrm{H}$ & & $\mathrm{OH}$ & Sigma \\
\hline Rutin & $\mathrm{H}$ & $\mathrm{OH}$ & $\mathrm{H}$ & & ORut $^{4}$ & Sigma \\
\hline Quercitrin & $\mathrm{H}$ & $\mathrm{OH}$ & $\mathrm{H}$ & & ORham $^{5}$ & Sigma \\
\hline Hyperoside & $\mathrm{H}$ & $\mathrm{OH}$ & $\mathrm{H}$ & & $\mathrm{OGal}^{6}$ & Sigma \\
\hline
\end{tabular}




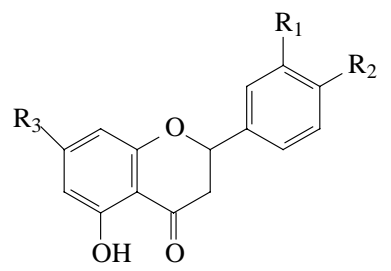

Flavone

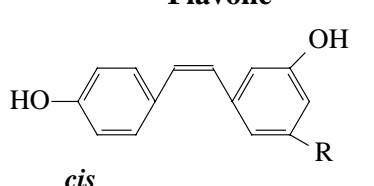

cis

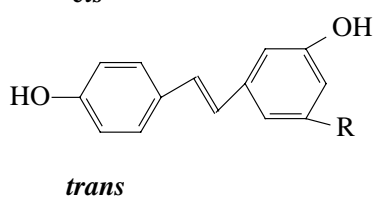

Resveratrol and glycoside

\begin{tabular}{lllll}
\hline Flavanones & $\mathrm{R}_{1}$ & $\mathrm{R}_{2}$ & $\mathrm{R}_{3}$ & Source \\
\hline Hesperetin & $\mathrm{OH}$ & $\mathrm{OCH}_{3}$ & $\mathrm{OH}$ & Sigma \\
Neohesperidin & $\mathrm{OH}$ & $\mathrm{OCH}_{3}$ & $\mathrm{ONeo}^{7}$ & Sigma \\
$\begin{array}{l} \pm \text {-Naringenin } \\
\text { Naringin }\end{array}$ & $\mathrm{H}$ & $\mathrm{OH}$ & $\mathrm{OH}$ & Sigma \\
\hline Stilbenes & $\mathrm{H}$ & $\mathrm{OH}$ & $\mathrm{ONeo}$ & Sigma \\
\hline $\begin{array}{l}\text { trans-Resveratrol } \\
\text { cis-Resveratrol }\end{array}$ & & $\mathrm{R}$ & Source \\
trans-Piceid $^{8}$ & & $\mathrm{OH}$ & Sigma \\
cis-Piceid $^{10}$ & \multicolumn{5}{c}{$\mathrm{OH}$} & \\
\hline
\end{tabular}

${ }^{1}$ Sigma Chemical Co., (St. Louis, MI, USA); ${ }^{2}$ Aldrich (Milwaukee, WI, USA); ${ }^{3}$ Fluka (Buch, Switzerland); ${ }^{4}$ Rut $=$ Rutinose; ${ }^{5}$ Rham $=$ Rhamnose; ${ }^{6} \mathrm{Gal}=$ galactose; ${ }^{7}$ Neo = Neohesperidose; ${ }^{9}$ cis-Resveratrol was obtained by exposing the trans form to a $366 \mathrm{~nm}$ UV lamp for $2 \mathrm{~h} ;{ }^{8} \mathrm{Glu}=$ glucose; ${ }^{10}$ cis-piceid was obtained by exposing the trans form to a $366 \mathrm{~nm}$ UV lamp for $1.5 \mathrm{~h}$.

\section{Hydroxybenzoic acids}

In the negative ion mode hydroxybenzoic acids produced a deprotonated $[M-\mathrm{H}]^{-}$molecule and a $[M-\mathrm{H}-44]^{-}$fragment ion via loss of a $\mathrm{CO}_{2}$ group from the carboxylic acid moiety (Figure 2a). Aside from the $m / z 135$ peak ([M-H-44] $)$, the fragmentation of syringic acid produced an anion radical with $\mathrm{m} / \mathrm{z} 182$ ([M-H-15]') by losing a $\mathrm{CH}_{3}$ group from the $\mathrm{m} / \mathrm{z} 197$ precursor ion. The UV spectra of the hydroxybenzoic acids were quite relevant to their chemical structures. Single absorption peaks appeared in the UV spectra of compounds such as gallic acid, p-hydroxybenzoic acid and syringic acid, all of which have symmetrical chemical structures, whereas in the case of phenols such as protocatechuic acid, vanillic acid and gentisic acid, which have non-symmetrical chemical structures, two absorption peaks were noted in the corresponding UV spectra. The position and number of hydroxyl groups on the aromatic rings also had a significant effect on wavelength shift (Figure 1 and Table 1).

\section{Hydroxycinnamic acids}

Like the hydroxybenzoic acids, hydroxycinnamic acids such as caffeic acid (Figure 2b), also produced a deprotonated $[\mathrm{M}-\mathrm{H}]^{-}$molecule and lost a $\mathrm{CO}_{2}$ group (from the carboxylic acid function) in the negative ion mode (Table 1). Ferulic acid and sinapic acid showed the loss of the $\mathrm{CH}_{3}$ group, providing a [M-H-15] ${ }^{-}$anion radical at $m / z 178$ and $m / z$ 208, respectively. Chlorogenic acid showed the $[M-H]^{-}$deprotonated molecule $(\mathrm{m} / \mathrm{z} 353)$ and the ion corresponding to the deprotonated quinic acid ( $\mathrm{m} / \mathrm{z}$ 191), which was consistent with a previous report [19]. In the UV spectra sinapic acid and coumaric acid, with symmetrical chemical structures, and trans-cinnamic acid, without a hydroxyl group, showed a single absorption peak, while caffeic, chlorogenic and ferulic acid, with 
non-symmetrical chemical structures, had a major absorption peak and a shoulder absorption under our conditions, which was inconsistent with the previous report [20, 26]. The reason for this discrepancy may be the substitution of hydroxyl or methoxyl groups of the cinnamic-type which caused hypsochromic shifts (Figure1 and Table 1).

Table 1. LC-UV-MS/MS spectral information of 39 phenolic standards

\begin{tabular}{|c|c|c|c|c|}
\hline Compound names & RT (min) & MW & {$[M-H]^{-}\left(\right.$Frag. MS $\left.^{2} m / z\right)$} & UV band (nm) \\
\hline \multicolumn{5}{|l|}{ Hydroxybenzoic acid } \\
\hline Gallic acid & 5.9 & 170 & 169 (125) & 272 \\
\hline Protocatechuic acid & 10.1 & 154 & $153(109)$ & 260 (max), 294 \\
\hline Vanillic acid & 23.2 & 168 & $167(123)$ & 260 (max), 294 \\
\hline Syringic acid & 28.0 & 198 & $197(182,153)$ & 276 \\
\hline p-Hydroxybenzoic acid & 16.0 & 138 & 137 (93) & 256 \\
\hline Salicylic acid & 41.7 & 138 & 137 (93) & 276 \\
\hline Gentisic acid & 16.7 & 154 & $153(109)$ & 326 (max), 300 \\
\hline \multicolumn{5}{|l|}{ Hydroxycinnamic acid } \\
\hline Caffeic acid & 23.9 & 180 & 179 (135) & 324 (max), 296 \\
\hline p-Coumaric acid & 34.5 & 164 & 163 (119) & 310 \\
\hline Sinapic acid & 38.5 & 224 & $223(208,179,149)$ & 324 \\
\hline Ferulic acid & 38.7 & 194 & $193(134,149,179)$ & 324 (max), 296 \\
\hline trans-Cinnamic acid & 50.6 & 148 & 147 & 278 \\
\hline Chlorogenic acid & 21.4 & 354 & 353 (190) & 326 (max), 300 \\
\hline \multicolumn{5}{|l|}{ Flavan-3-ols } \\
\hline$(+)$-Catechin & 16.9 & 290 & $289(245,205,179)$ & 280 \\
\hline (-)-Epicatechin & 28.5 & 290 & $289(245,205,179)$ & 280 \\
\hline (-)-Gallocatechin gallate & 32.73 & 458 & 457 (169, 331, 305) & 276 \\
\hline (-)-Epigallocatechin gallate & 26.97 & 458 & 457 (169, 331, 305) & 276 \\
\hline (-)-Epicatechin gallate & 36.32 & 442 & $441(289,169)$ & 278 \\
\hline (-)-Gallocatechin & 7.74 & 306 & $305(125,179)$ & 274 \\
\hline (-)-Epigallocatechin & 8.5 & 306 & $305(125,179)$ & 274 \\
\hline Procyanidin B1 & 12.1 & 578 & $577(407,425,451,289)$ & 280 \\
\hline Procyanidin B2 & 20.8 & 578 & $577(407,425,451,289)$ & 280 \\
\hline \multicolumn{5}{|c|}{ Flavonol and flavonol glycosides } \\
\hline Quercetin & 50.57 & 302 & $301(151,179)$ & 256 (max), 372 \\
\hline Myricetin & 46.5 & 318 & $317(151,179)$ & 256 (max), 374 \\
\hline Kamepferol & 53.0 & 286 & $285(257,151,169)$ & 266 (max), 366 \\
\hline Morin & 48.40 & 302 & $301(125,151)$ & 256 (max), 354 \\
\hline Rutin & 45.0 & 610 & $609(301,179,151)$ & 256 (max), 356 \\
\hline Quercitrin & 46.9 & 448 & $447(301,179,151)$ & 256 (max), 352 \\
\hline Hyperoside & 44.3 & 464 & $463(301,179,151)$ & 256 (max), 356 \\
\hline$( \pm)$-Taxifolin & 35.76 & 304 & $302(285,125,178)$ & 288 \\
\hline \multicolumn{5}{|c|}{ Flavanone and flavanone glycosides } \\
\hline Hesperetin & 51.9 & 302.3 & $301(258,143)$ & 288 \\
\hline Neohesperidin & 46.0 & 610.6 & $609(301)$ & 288 \\
\hline$( \pm)$-Naringenin & 51.19 & 272.3 & $271(151,177)$ & 290 \\
\hline Naringin & 44.09 & 580 & $579(459,271,235)$ & 284 \\
\hline Leutolin & 52.0 & 286 & $285(217,241,175)$ & 348 \\
\hline
\end{tabular}


Table 1. Cont.

\begin{tabular}{lllll}
\hline Resveratrols & & & & \\
trans-Resveratrol & 44.4 & 228 & $227(185,159)$ & 306 \\
cis-Resveratrol & 48.7 & 228 & $277(185,159)$ & 284 \\
trans-Piceid & 37.9 & 390 & $389(227)$ & 306 \\
cis-Piceid & 45.7 & 390 & $389(227)$ & 284 \\
\hline
\end{tabular}

3. Flavan-3-ols.

(+)-Catechin ([M-H] $]^{-} \mathrm{m} / \mathrm{z}$ 289) yielded fragment ions at $\mathrm{m} / \mathrm{z} 245,179,205$. The isomer (-)-epicatechin gave the same fragment ions, as the stereoisomers could not be distinguished by mass spectrometry. The [M-H-44] fragment ion at $\mathrm{m} / \mathrm{z} 245$ in (+)-catechin or (-)-epicatechin (Figure 2c) was produced by the loss of a $(\mathrm{CH})_{2} \mathrm{OH}$ group as described by Perez-Magari [23]; the mechanism of production of fragment ions at m/z 179 and 205 has been explained by Stöggl [22] and Bravo [27]. (-)-Gallocatechin and its isomer (-)-epigallocatechin ([M-H] $\left.]^{-} \mathrm{m} / \mathrm{z} 305\right)$ yielded the fragment ions at $\mathrm{m} / \mathrm{z}$ 125 and 179, which was consistent with the previous report [28]. (-)-Epicatechin-3-O-gallate ([M-H] $\mathrm{m} / \mathrm{z} 441$ ) gave fragment ions at $\mathrm{m} / \mathrm{z} 289$ which resulted from the cleavage of the ester bond and the loss of a gallic acid moiety, and those at $\mathrm{m} / \mathrm{z} 169$ from the cleavage of the ester bond and the loss of (-)-epictechin units.

Similarly, (-)-gallocatechin-3-O-gallate and its isomer (-)-epigallocatechin-3-O-gallate ([M-H] $]^{-} \mathrm{m} / \mathrm{z}$ 457) produced, by the cleavage of the ester bond, a fragment ion at $m / z 169$ that corresponds to gallic acid and the fragment ion at $\mathrm{m} / \mathrm{z} 305$ corresponding to the (-)-gallocatechin or (-)-epigallocatechin units. In addition, a fragment ion at $\mathrm{m} / \mathrm{z} 331$ was observed. The (-)ESI-MS/MS spectra of dimeric procyanidin B1 and procyanidin B2 ([M-H] $]^{-}, m / z 577$ ), gave [M-H-152] fragment ions at $m / z 425$ from Retro-Diels-Alder (RDA) rearrangement of the heterocyclic ring, at $\mathrm{m} / \mathrm{z} 407$ ([M-H-170]$]^{-}$) from RDA-F of the heterocyclic ring and loss of $\mathrm{H}_{2} \mathrm{O}$, at $\mathrm{m} / \mathrm{z} 451$ ([M-H-126] $]^{-}$) from cleavages between $\mathrm{C}_{4}-\mathrm{C}_{5}$ and $\mathrm{O}-\mathrm{C}_{2}$ of one pyran ring and at $\mathrm{m} / \mathrm{z} 289$ ([M-H-289] $\left.{ }^{-}\right)$from cleavage of the interflavanic bond (Figure 2d) by a mechanism already described by Sun and Miller [29], respectively.

The UV absorption spectra of all flavan-3-ols showed a single peak with a wavelength of $280 \mathrm{~nm}$. When one hydroxyl group at the 5'-position was substituted and a hydroxyl group at the 3-position of the flavan-3-ol skeleton (Figure 1) was esterified by gallate, the absorption peak shifts to a shorter wavelength (by 4-6 nm). Polymerization between flavan-3-ols could not cause any change in the UV absorption spectra (Figure 1 and Table 1).

\section{Flavonols and flavonol glycosides}

As shown in Figures 2e,f the aglycones quercetin and myricetin both produced fragment ions at $\mathrm{m} / \mathrm{z}$ 151 and 179, which result from a cleavage of the heterocyclic C-ring by RDA [27], while kaempferol and morin only had a fragment ion at $\mathrm{m} / \mathrm{z} 151$, also from a cleavage of the heterocyclic C-ring by RDA, but the fragmentation mechanism remains unclear at present. For flavonol-O-glycosides such as rutin, hyperoside and quercitrin, their spectra showed the deprotonated $[\mathrm{M}-\mathrm{H}]^{-}$molecule of the glycoside and the $[\mathrm{A}-\mathrm{H}]^{-}$ion corresponding to the deprotonated aglycone. The latter ion is formed by losing the rutinose, galactose and rhamnose moiety from the corresponding glycosides (Table 1). 
Figure 2. LC-UV and MS/MS spectra of eight representative phenolic standards
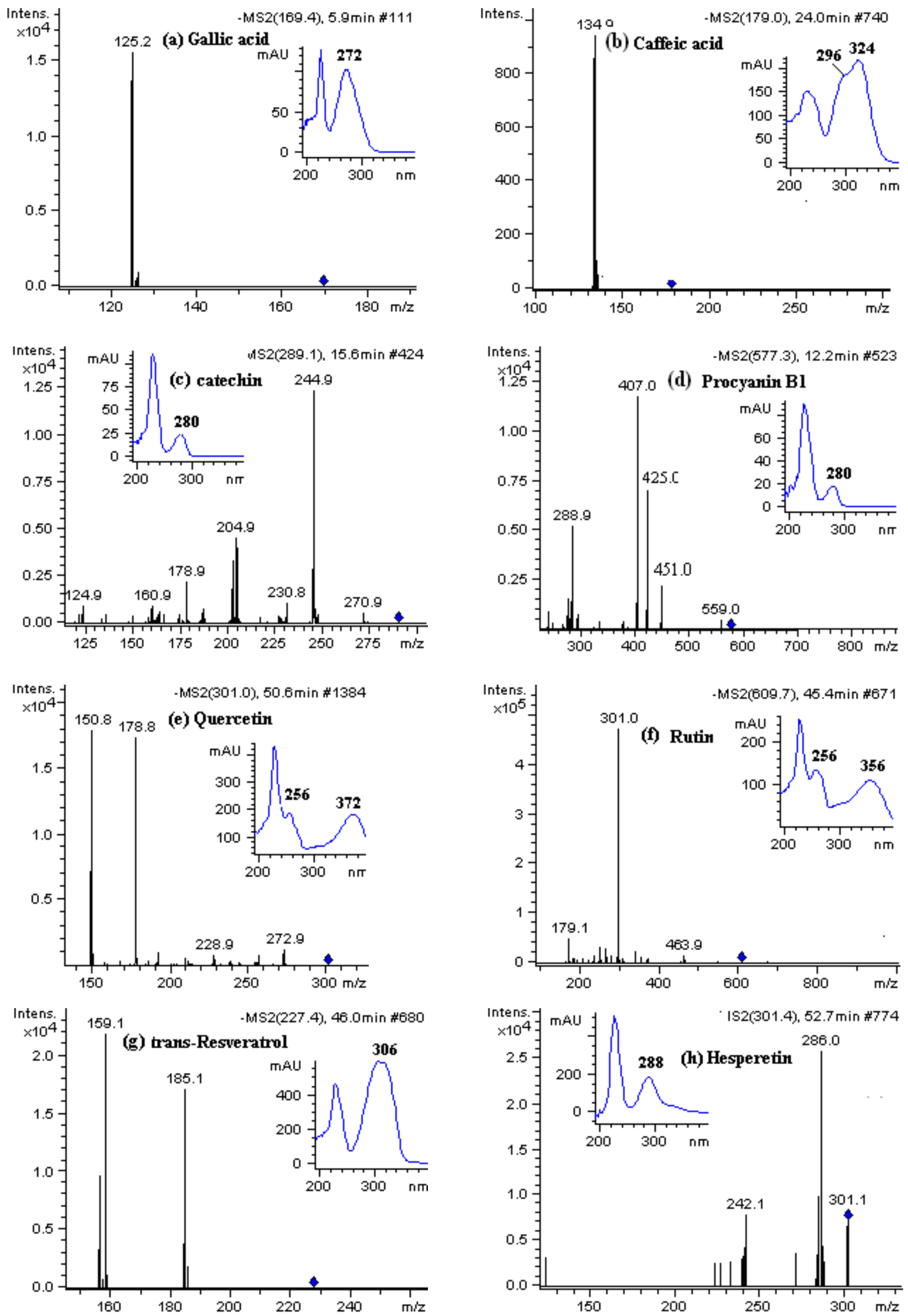
Due to the conjugate structure formed between the double bond at the 2,3-position and the carbonyl group at the 4-position of flavonols and their glycosides structures, their UV spectra presented two major absorption peaks with a band I and a band II (Figures 2e,f). The glycosylated quercetin showed a shorter 24-52 nm shift of band I (rutin, quercitrin, hyperoside ) and a $32 \mathrm{~nm}$ hypsochromic shift of band II (hyperoside) as compared with its aglycone. Moreover, the position and number of hydroxyl groups in the B-rings leads to the same shift in kaempferol and morin.

\section{Stilbenes}

Resveratrol produced $\mathrm{m} / \mathrm{z} 185$ and 156 fragment ions (Figure 2g). Like the flavonol glycosides, the spectra of trans/cis-resveratrol glycoside (trans/cis-piceid, $\mathrm{m} / \mathrm{z}$ 389) gave a fragment ion at $\mathrm{m} / \mathrm{z} 227$ from loss of the glucose moiety. A typical UV spectrum of trans-resveratrol and trans-piceid presented a maximum at $306 \mathrm{~nm}$, with shorter shifts than their isomers. Glycosylation had no effect on the UV spectra (Table 1)

\section{Flavanones}

Different fragment ions were observed for hesperetin, with $\mathrm{m} / \mathrm{z} 258$ and 143 (Figure 2g), and naringenin, with $\mathrm{m} / \mathrm{z} 177$ and 151, despite the similar chemical structures of both compounds. Neohesperidin and naringin showed the [M-H-308] fragment ion due to the loss of the neohesperidose moiety. The UV spectrum of flavone exhibits a single absorption peak between $280 \mathrm{~nm}$ and $290 \mathrm{~nm}$, but with a peak trend to about $320 \mathrm{~nm}$ resulting from the carbonyl group at the 4-position (Figures 2e, $\mathrm{f}$ and g).

Identification of phenolic compounds in wine samples using the LC/UV and MS/MS libraries

Based on the optimum LC-UV-ESI-MS/MS conditions established for the phenolic compounds using standard solutions we next analyzed wine extracts. The LC-UV chromatogram profiles at 280 $\mathrm{nm}$ of the ethyl acetate extracts of samples A-F are shown in Figure 3 (peaks cited correspond to those listed in Table 2). Using our standard library information (e.g. peak retention times, UV spectrum, ESI-MS/MS data), we identified five hydroxybenzoic acids (peaks 1, 2, 5, 8, 10), two hydroxycinnamic acids (peaks 9, 13), four flavan-3-ols (peaks 4, 6, 7, 11), five flavanols (peaks 21, 23, 25, 29, 31), four resveratrols (peaks 16, 22, 24, 27), and one flavanone (peak 30) in six different red wines (Table 2). Additionally, peaks 3, 12, 17, 18, 20 were tentatively identified by comparison of the LC/UV and MS/MS libraries created (Table 1).

Peak 3 presented the cinnamic-type UV spectrum, $[M-\mathrm{H}]^{-}$molecular ion at $\mathrm{m} / \mathrm{z} 311$ and fragment ions at $\mathrm{m} / \mathrm{z} 179$ ([M-H-132 $\left.]^{-}\right)$and 135 (M-H-132-44) $)$ which coincided with the mass of caffeic acid, and was thus identified as caftaric acid, previously described in wine [21, 31, 32]. The ESI-MS/MS spectra of caftaric acid resulted from loss of a tartaric acid unit after cleavage of the ester bond and subsequent loss of the $\mathrm{CO}_{2}$ group. Similarly, peak 12 with $[M-\mathrm{H}]^{-}$at $\mathrm{m} / \mathrm{z} 197$ and fragment ions at $\mathrm{m} / \mathrm{z}$ 169 ([M-H-28] $\left.]^{-}\right)$and at $\mathrm{m} / \mathrm{z} 125$ ([M-H-28-44] $\left.]^{-}\right)$was considered to be ethyl gallate, which loses an ethyl unit and a gallic acid unit and then a $\mathrm{CO}_{2}$ group. Peak 17 showed the same UV spectrum and 
ESI-MS/MS spectrometric data as procyanidins $\mathrm{B} 1$ and $\mathrm{B} 2$, but a difference in retention time $(\mathrm{RT}=$ 38.2) was observed, so, peak 17 was assumed to be from a procyanidin dimer. Peaks 18 and 20 presented a similar flavanol UV spectrum (two absorption bands), $[M-H]^{-}$molecular ion at $\mathrm{m} / \mathrm{z} 479$ and [M-H-162] $]^{-}$(characteristic of glucoside/galactose derivatives) and $m / z \quad 317$ fragment ions (characteristic of a myricetin derivative), $[M-\mathrm{H}]^{-}$molecular ion at $m / z 477$ and $[M-\mathrm{H}-176]^{-}$fragment ion at $\mathrm{m} / \mathrm{z} 301$ (characteristic of glucuronide derivatives) and $\mathrm{m} / \mathrm{z} 301$ (characteristic of a quercetin derivitive), and thus could be tentatively assigned to myricetin-3-O-glucoside and quercetin-3-O-glucuronide. The other five unknown compounds (peaks 14, 15, 19, 26, 28) still couldn't be identified under the present conditions and need to be further identified by other tools.

\section{Application of phenolic compound fingerprinting in red wine by LC/UV and MS/MS libraries}

After creating the LC/UV and LC/MS/MS libraries we established that they could be used to confirm the presence of phenolic compounds in different wine samples. By searching the libraries, most of the 31 phenolic compounds were identified (Table 2), and a phenolic compound fingerprint was observed in six different red wines simultaneously (Figure 3).

Figure 3. LC-UV chromatogram at $280 \mathrm{~nm}$ from sample extracts, (a) sample A; (b) sample B; (c) sample C; (d) sample D; (e) sample E; (f) sample F. The LC/UV and MS/MS spectral information are listed at Table 2, and for the LC-UV conditions see the Experimental.
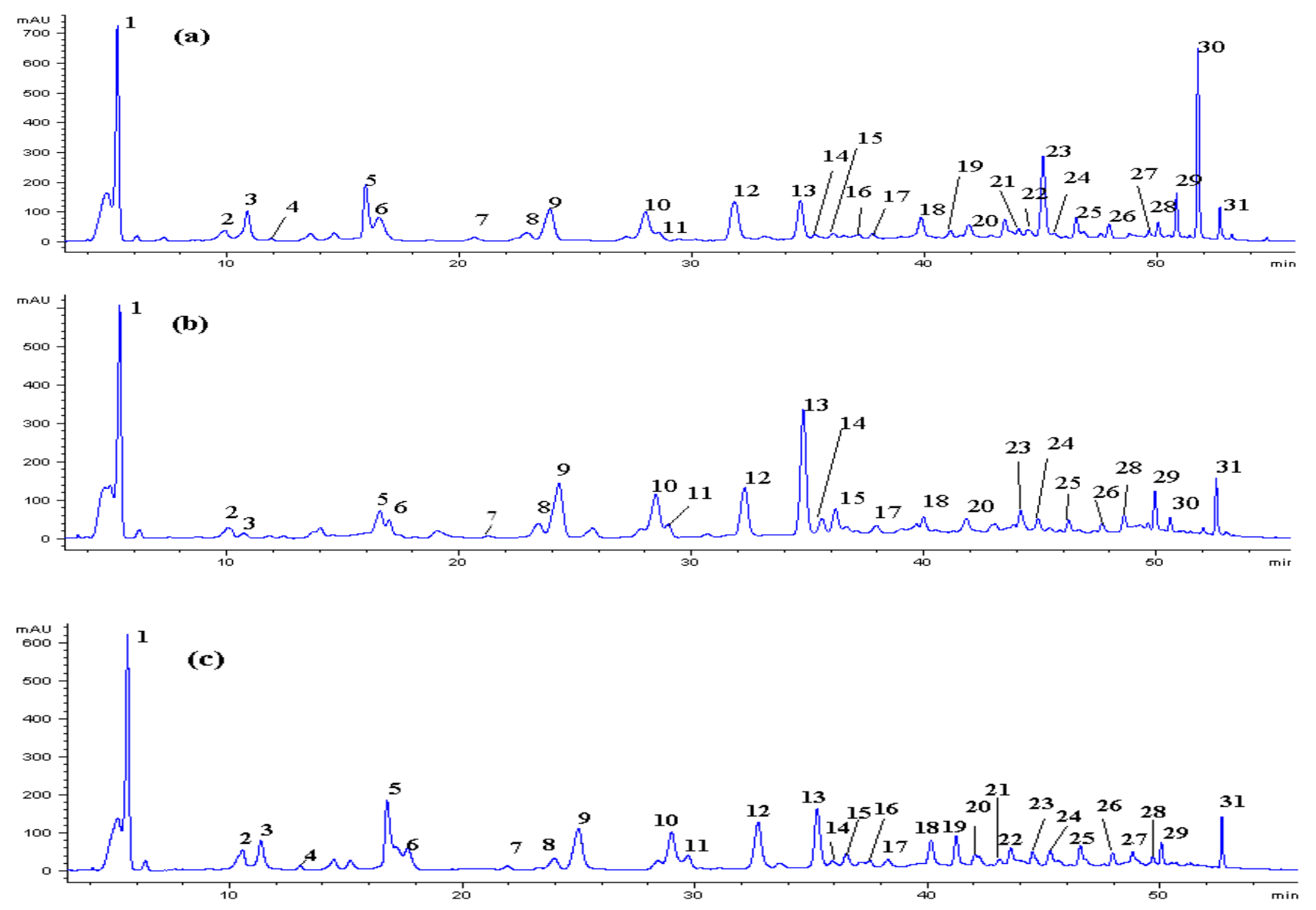

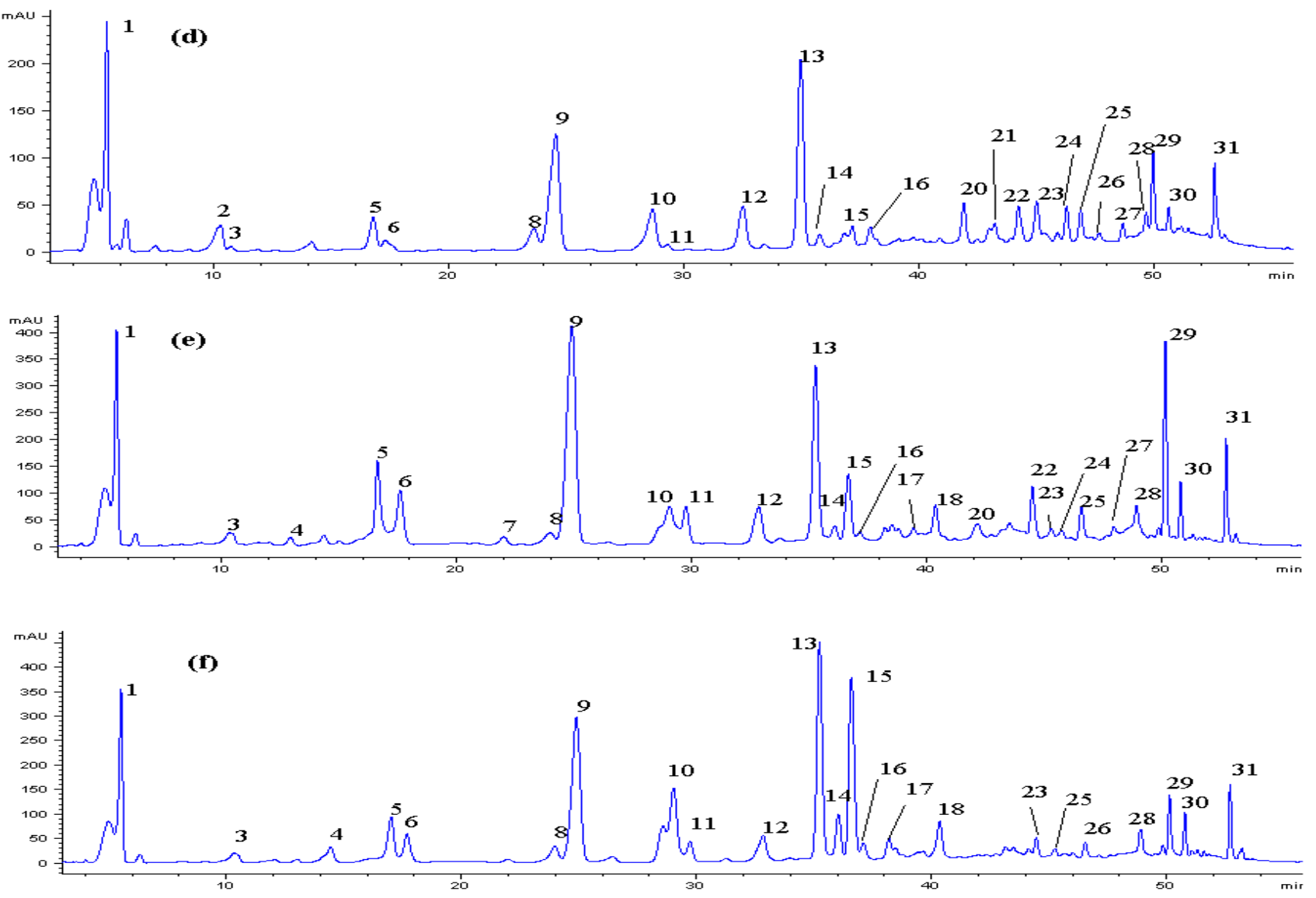

First of all, significant differences were found in differently aged wines such as samples A, C and E (the same variety and vineyard, but of different ages). As shown in Figure 3, peak 30 (hesperetin) was a characteristic peak in sample A, but was not detected in sample C. In comparison with samples A and C, two older wines, sample E, a young wine, had as higher intensity peaks 9 (caffeic acid), 13 (p-coumaric acid) and 15 (unknown) and as lower intensity peaks 1 (gallic acid) and 30 (quercetin). In addition, a few of the compounds, including peak 2 (procatechuic acid), 19 (unknown), and 21 (hyperoside)) were not identified in the young wine (Figures 3a,c,e). So, it can be seen that the amount of phenolic compounds in wines was more abundant, and the proportion each of them was more balanced as the wines aged. Secondly, some fingerprint information was also observed from the different varieties of wines such as samples B (Cabernet Gernischet), C (Cabernet Sauvignon) and D (Merlot). It was found that the total amounts of compounds detected in sample D was markedly lower than in samples B and C; and the level of compounds detected was most abundant in sample C, followed by samples $\mathrm{D}$ and $\mathrm{B}$, which were mainly deficient in compounds such as procyanidin dimer and resveratrols, respectively (Figures 3b,c,d). Finally, the fermentation container also had important effects on phenolic compound levels. Peak 14 (unknown) and 15 (unknown) increased remarkably in sample $\mathrm{F}$ (fermented in oak barrels) in comparison with sample $\mathrm{E}$ (fermented in stainless steels containers), while peak 29 (quercetin) gave the opposite result. Peaks 9 (caffeic acid) and peak 13 (p-coumaric acid) showed the opposite composite proportion in both samples. Furthermore, peaks 7 (procyanidin B2), 20 (myricetin-3-glucoside), 22 (trans-piecid), 24 (cis-piecid), and 27 (trans-resveratrol) were not detected in sample F (Figures 3e,f). In general, the presence of phenolic compounds in wines were influenced by some additional factors such as geographical origin of the wine, grape varieties, years of aging and winemaking technique. 
Table 2. Phenolic compounds identified in the present work in wines extracts by LC-UV-MS/MS

\begin{tabular}{|c|c|c|c|c|}
\hline Peak No. & RT (min) & {$[M-H]^{-} \quad\left(\right.$ Frag. MS $\left.^{2} m / z\right)$} & UV band (nm) & Compounds Name \\
\hline 1 & 5.8 & 169 (125) & 272 & Gallic acid \\
\hline 2 & 11.0 & 153 (109) & 260 (max), 294 & Protocatechuic acid \\
\hline 3 & 11.3 & $311(178,148)$ & 326 & Caftaric acid \\
\hline 4 & 12.1 & $577(407,425,451,289)$ & 280 & Procyanidin B1 \\
\hline 5 & 16.0 & 137 (93) & 256 & p-Hydroxybenzoic acid \\
\hline 6 & 16.9 & $289(245,179,125)$ & 280 & $(+)$-Catechin \\
\hline 7 & 20.8 & $577(407,425,451,289)$ & 280 & Procyanidin B2 \\
\hline 8 & 23.2 & 167 (123) & 260 (max), 294 & Vanillic acid \\
\hline 9 & 23.9 & 179 (135) & 324 (max), 296 & Caffeic acid \\
\hline 10 & 28.0 & $197(182,153,135)$ & 276 & Syringic acid \\
\hline 11 & 28.5 & $289(245,179,125)$ & 280 & (-)-Epicatechin \\
\hline 12 & 31.9 & $197(169,124)$ & 270 & Ethyl gallate \\
\hline 13 & 34.5 & 163 (119) & 310 & p-Coumaric acid \\
\hline 14 & 36.6 & $189(171,129)$ & 296 & Unknown \\
\hline 15 & 37.1 & $204(186,158,116)$ & 280 & Unknown \\
\hline 16 & 37.45 & 389 (227) & 306 & trans-Piceid \\
\hline 17 & 38.2 & $577(407,425,451,289)$ & 280 & Procyanidin dimer \\
\hline 18 & 39.8 & $479(317,179,151)$ & 266 (max), 354 & Myricetin-3-glucoside \\
\hline 19 & 41.8 & 579 (399, 373, 205) & 278 & Unknown \\
\hline 20 & 43.4 & $477(301,178,151)$ & 354 (max),260 & Quercetin-3-glucuronide \\
\hline 21 & 44.0 & $463(301,178,151)$ & 354 & Hyperoside \\
\hline 22 & 44.4 & $227(184,159)$ & 306 & trans-Resveratrol \\
\hline 23 & 45.0 & $609(301)$ & 256 (max), 324 & Rutin \\
\hline 24 & 45.5 & 389 (227) & 284 & cis-Piceid \\
\hline 25 & 46.5 & $317(179,151)$ & 256 (max), 376 & Myricetin \\
\hline 26 & 47.9 & $507(344,229,301)$ & 358 & Unknown \\
\hline 27 & 48.7 & $227(184,159)$ & 284 & cis-Resveratrol \\
\hline 28 & 50.0 & $207(179,161,135)$ & 326 & Unknown \\
\hline 29 & 50.8 & $301(179,151,107)$ & 256 (max), 372 & Quercetin \\
\hline 30 & 51.7 & $301(286,258,242)$ & 288 & Hesperetin \\
\hline 31 & 52.9 & $285(151,169,241)$ & 266 (max), 366 & Kamepferol \\
\hline
\end{tabular}

\section{Conclusions}

Due to its sensitivity and ease of coupling to a DAD detector, RP-HPLC remains the analytical method of choice for the analysis of the phenolic compounds in wine extracts. LC-MS with the use MS/MS provides structural information on novel compounds, which couldn't be identified simply by investigation of their UV spectra. In this research, liquid chromatography coupled with ion spray mass spectrometry in the negative mode was used for the identification of 39 phenolic standards including hydroxybenzoic and hydroxycinnamic acids, flavan-3-ols, flavanols and resveratrols, as well as for creating LC/UV and LC/MS/MS libraries for the identification of real samples under the same conditions. By searching the LC/UV and LC/MS/MS libraries, the identification of phenolic compounds in different wines was accomplished. Therefore these libraries not only minimize the amount of work which would otherwise be required for manual interpretation, but also provide the 
basis for identifying phenolic compounds in samples of differing origins, varieties, cultivation and winemaking techniques. Further work would involve the addition of new phenolic standards to the $\mathrm{LC} / \mathrm{UV}$ and LC/MS/MS libraries in order to confirm the presence of the other compounds in the wines. For those compounds that could not be distinguished in the mass spectra, some isolation of the compounds would be required to further identify by other tools such as nuclear magnetic resonance (NMR) for the further work.

\section{Experimental Section}

Reagents and standards

Methanol and glacial acetic acid (HPLC grade purity) were purchased from Fisher (Fairlawn, NJ, USA). Deionized water ( $<18 \mathrm{M} \Omega$ resistance) was obtained from a Milli-Q Element water purification system (Millipore, Bedford, MA). The procyanidin dimer B1 and B2 standards were purchased from Extrasynthese (Genay, France) while chlorogenic acid and ( \pm )-taxifolin were from Sigma Chemical Co. (St.Louis, MI, USA). The structures and purchase sources for the remaining standards are listed in Figure 1.

\section{Wine samples}

The six red wine samples $(\mathrm{A}-\mathrm{F})$, including four commercial and two experimental wines, were: Sample A: Huaxia Great Wall Wine I, a 13 yr-old Cabernet Sauvignon from Changli, Hebei; Sample B : Changyu Wine, a 10 yr-old Cabernet Gernischet from Yantai, Shandong; Sample C: Huaxia Great Wall Wine II, a 10 yr-old Cabernet Sauvignon from Changli, Hebei; Sample D: Qilian Wine, a 10 yr-old Merlot from Gaotai, Gansu; Sample E: experimental wine fermented using stainless steel, a 1 yr-old Cabernet Sauvignon from Changli, Hebei; Sample F: experimental wine fermented in oak, a 1 yr-old Cabernet Sauvignon from Changli, Hebei.

\section{Extraction of wine phenols}

Extractions of wine polyphenols were carried out according to the method reported by Garcia-Viguera and Bridle [13] with the following modifications: deionized water (100 mL) was added to wine $(100 \mathrm{~mL})$ and the mixture was extracted with ethyl acetate $(80 \mathrm{~mL})$. The ester phase was concentrated on a rotary vaporator under $30^{\circ} \mathrm{C}$ and the residue dissolved in $1: 1(\mathrm{v} / \mathrm{v})$ methanol/water $(5.0 \mathrm{~mL})$.

\section{HPLC-DAD-ESI-MS/MS analyses}

Polyphenol analysis by LC-ESI-MS/MS were carried out using an Agilent 1100 series LC and LC/MSD Trap VL mass spectrometer (Agilent Technologies, Palo Alto, CA, USA) equipped with electrospray ionization (ESI) interface. The LC system includes a G1379A on-line degasser, a G1311A quaternary pump, a 1313A autosampler, a G1316A thermostatic column control, and a G1315A DAD, 
all of which were controlled by the Agilent ChemStation version 5.2 software. The HPLC separation was performed on a reversed-phase Zorbax SB-C 18 column (250 x $4.6 \mathrm{~mm}$ i.d. $5 \mu \mathrm{m}$ particle size, Agilent Technologies, USA) at $25{ }^{\circ} \mathrm{C}$. The mobile phase consisted of $1 \%$ acetic acid in water (solvent A) and $1 \%$ acetic acid in methanol (solvent B) applying the following gradient: 0-25 min: 10-22 \% B, 25-45 min: 22-50 \% B, 45-55 min: 50-95 \% B, 55-60 min: $95 \%$ B isocratic, 60-63 min: 95-10 \% B, 63-66 min: $10 \%$ B isocratic. The flow rate was $1.0 \mathrm{~mL} \mathrm{~min}^{-1}$. Injection volume was $10 \mu \mathrm{L}$ with the UV detector set to an absorbance wavelength of $280 \mathrm{~nm}$. The ESI parameters were as follows (optimized depending on compounds): nebulizer, 30 psi; dry gas $\left(\mathrm{N}_{2}\right)$ flow, $10 \mathrm{~L} \mathrm{~min}^{-1}$; and dry gas temp., $325^{\circ} \mathrm{C}$; the ion trap mass spectrometer was operated in negative ion mode with a scanning range from $\mathrm{m} / \mathrm{z} 200$ to $\mathrm{m} / \mathrm{z}$ 800. In addition, the activation energy for the MS/MS experiment was set to $1.0 \mathrm{~V}$.

\section{Acknowledgements}

This research was supported by the China National Natural Science Foundation (grant No. 39900101 to C.-Q.D)

\section{References}

1. Robichaud, J. L.; Noble, A. C. Astringency and selected phenolics in wine. J. Sci. Food Agr. 1990, 53, 343-353.

2. Thorngate III, J. H.; Noble, A. C. Sensory evaluation of Bitterness and Astringency of 3R (-)epicatechin and $3 S$ (+)-catechin. J. Sci. Food Agric. 1995, 67, 531-535.

3. Pocock, K. F.; Sefton, M. A.; Williams, P. Taste thresholds of phenolic extracts of French and American oakwood: the influence of oak phenols on wine flavor. J. Am. J. Enol. Vitic. 1994, 45, 429-434.

4. Maffei Facino, R.; Carini, M.; Aldini, G.; Bombardelli, E.; Morazzon, P.; Morelli, I. R. Free radicals scavenging action and antienzyme activities of procyanidines from Vitis vinifera. Arzneimittel. 1994, 44, 592-601.

5. Frankel, E. N.; Waterhouse, A. L.; Teissedre, P. L. Principal phenolic phytochemicals in selected California wines and their antioxidant activity in inhibiting oxidation of human low-density lipoproteins. J. Agr. Food Chem. 1995, 43, 890-894.

6. Meyer, A. S.; Sook, Y. O.; Pearson, D. A.; Waterhouse, A. L.; Frankel, E. N. Inhibition of human low-density lipoprotein oxidation in relation to composition of phenolic antioxidants in grapes (Vitis vinifera). J. Agr. Food Chem. 1997, 45, 1638-1643.

7. Waterhouse, A. L.; Walzem, R. L. Nutrition of grape phenolic. In Flavonoids in health and disease; Rice-Evans, C.A.; Packer, L. (editors); Dekker: New York, 1997

8. Bagchi, D.; Krohn, R. L.; Garg, A.; Balmoori, J.; Bagchi, M.; Tran, M X.; Stohs, S. J. Comparative in vitro and in vivo free radical scavenging abilities of grape seed proanthocyanidins and selected antioxidants. FASEB J. (Abstr.) 1997, 11, 3369.

9. Schramm, D. D.; Donovan, J. L.; Kelly, P. A. Differential effects of small and large molecular weight wine phytochemicals on endothelial cell eicosanoid release. J. Agr. Food Chem. 1998, 46, 1900-1905. 
10. Joshi, S. S.; Benner, E. J.; Balmoori, J.; Bagchi, D. Amelioration of cytotoxic effects of idarubicin and $4 \mathrm{HC}$ on change liver cells by a novel grape seed proanthocyanidin extract. FASEB J. (Abstr.) 1998, 12, 4484.

11. Maffei Facino, R.; Carini, M. M.; Aldini, G.; Berti, F.; Rossoni, G.; Bombardelli, E.; Morazzoni, P. Diet enriched with procyanidis enhances antioxidant activity and reduces myocardial post-ischemic damage in rats. Life Sci. 1999, 64, 627-634.

12. Macheix, J.; Fleuriet, A.; Billot, J. The main phenolics of fruit. In: Fruit phenolics; CRC Press, Inc.: Boca Raton, FL, 1990; pp. 1-98.

13. García-Viguera, C.; Bridle, P. Analysis of non-coloured phenolic compounds in red wines. A compound of high-performance liquid chromatography and capillary zone electrophoresis. Food Chem. 1995, 54, 349-352.

14. Goldberg, D. M.; Tsang, E.; Karumanchiri, A.; Diamandis, E. P.; Soleas, G.; Ng, E. Method to assay the concentrations of phenolic constituents of biological interest in wines. Anal. Chem. Acta 1996, 68, 1688-1694.

15. Guillén, D. A.; Barroso, C. G.; Pérez-Bustamante, J. A. Selection of column and gradient for the separation of polyphenols in sherry wine by high-performance liquid chromatography incorporating internal standards. J. Chromatogr. A 1996, 724, 117-124.

16. Buiarelli, F.; Cartoni,G.; Coccioli, F.; Levetsovitou, Z. Determination of phenolic acids in by high-performance liquid cahromatography with a microbore column. J. Chromatogr. A 1995, 695, 229-235.

17. Cartoni, G. P.; Coccioli, F.; Pontelli, L.; Quattrucci, E. Separation and identification of free phenolic acids in wines by high-performance liquid chromatography. J. Chromatogr. A 1991, 537, 93-99.

18. Cooks, R. G.; Caprioli, R. Special Feature on electrospray ionization J. Mass Spectrom. 2000, 35, 761-761.

19. Sónchez-Rabaneda, F.; Jáuregui, O.; Casals, I.; Andrés-Lacueva, C.; Izquierdo- Pulido, M. Liquid chromatographic/electrospray ionization tandem mass spectrometric study of the phenolic composition of cocoa (Theobroma cacao). J. Mass Spectrom. 2003, 38, 35-42.

20. Loredana, L.; Torre, G. L. L.; Saitta, M.; Vilasi, F.; Pellicanó, T.; Dugo G. Direct detecrmination of phenolic compounds in Sicilian wines by liquid chromatography with PAD and MS detection. Food Chem. 2006, 94, 640-650.

21. Monagas, M.; Suárze, R.; Gómez-Cordovés, C.; Bartolomé, B. Simultaneous determination of nonanthocyanins in phenolic compounds in wines by HPLC-DAD/ESI-MS. Am. J. Enol. Vitic. 2005, 56 (2), 139-147.

22. Stöggl, W. M.; Huck, C. W.; Bonn, G. K. Structural elucidation of catechin and epicatechin in sorrel leaf extracts using liquid-chromatography coupled to diode array-, fluorescence-, and mass spectrometric detection. J. Sep. Sci. 2004, 27, 524-528.

23. Pérez-Magariño, S.; Revilla, I.; González-SanJosé, M. L.; Beltrán, S. Various applications of liquid chromatography-mass spectrometry to the analysis of phenolic compounds. J. Chromatogr. A 1999, 847, 75-81.

24. 24. Flamini R. Mass spectrometry in grape and wine chemistry. Part I: polyphenols. Mass Spectrom. Rev. 2003, 22, 218-250. 
25. 25. Wachs, T.; Conboy, J. C.; Garicia, F.; Henion, J. D. Liquid chromatography-mass spectrometry and related techniques via atmospheric pressure ionization. J Chromatogr. Sci. 1991, 29, 357-366.

26. 26. Robbins, R. J.; Bean, S. R. Development of a quantitative high-performance liquid chromatography-photodiode array detection measurement system for phenolic acids. $J$. Chromatogr. A 2004, 1038, 97-105.

27. 27. Bravo, M. N.; Silva, S.; Coelho, A.V.; Vilas Boas, L.; Bronze, M. R. Analysis of phenolic compounds in Muscatel wines produced in Portugal. Anal. Chim. Acta 2006, 563, 84-92.

28. 28. Miketova, P.; Schram, K.; Whitney, J.; Li, M.; Huang, R.; Klohr, S. Tandem mass spectrometry studies of green tea catechins. Identification of three minor components in the polyphenolic extract of green tea. J. Mass Spectrom. 2000, 35, 860-869.

29. 29. Sun, W. X.; Miller, J. M. Tandem mass spectrometry of the B-type procyanidins in wine and B-type dehydrodicatechins in an autoxidation mixture of (+)-catechin and (-)-epicatechin. J. Mass Spectrom. 2003, 38, 438-446.

30. 30. Stevens, J. F.; Ivancic, M.; Hsu, V. L.; Deinzer, M. L. Prenyflavonoids from Humulus Lupulus. Phytochemistry 1997, 8, 1575-1585.

31. 31. Tefaye, W.; Morales, M. L.; Garciaa-Parrilla, M. C.; Troncoso, A. M.; J. Agric. Evolution of phenolic compounds during an experimental aging in wood of sherry vinegar. Food Chem. 2002, 50, 7053-7061.

32. 32. Penóa-Neira, A.; Hernández, T.; García-Vallejo, C.; Suarez, I. E. J. A. A survey of pheolic compounds Spanish wines of different geographical origin. Eur. Food Res. Technol. 2000, 210, $445-448$.

Sample Availability: Samples are available from authors.

(C) 2007 by MDPI (http://www.mdpi.org). Reproduction is permitted for noncommercial purposes. 